\title{
Lack of Collagen XV Impairs Peripheral Nerve Maturation and, When Combined with Laminin-411 Deficiency, Leads to Basement Membrane Abnormalities and Sensorimotor Dysfunction
}

\author{
Karolina Rasi, ${ }^{1}$ Merja Hurskainen, ${ }^{1}$ Mika Kallio, ${ }^{4}$ Saara Stavén, ${ }^{6}$ Raija Sormunen, ${ }^{2}$ Anthony M. Heape, ${ }^{3}$ Robin L. Avila,${ }^{5}$ \\ Daniel Kirschner, ${ }^{5}$ Anu Muona, ${ }^{1}$ Uolevi Tolonen, ${ }^{4}$ Heikki Tanila, ${ }^{6,7}$ Pirkko Huhtala, ${ }^{1}$ Raija Soininen, ${ }^{1}$ and \\ Taina Pihlajaniemi ${ }^{1}$ \\ ${ }^{1}$ Oulu Center for Cell-Matrix Research, Biocenter Oulu, Department of Medical Biochemistry and Molecular Biology, ${ }^{2}$ Biocenter Oulu, Department of \\ Pathology and ${ }^{3}$ Department of Anatomy and Cell Biology, University of Oulu, FIN-90014 Oulu, Finland, ${ }^{4}$ Department of Clinical Neurophysiology, Oulu \\ University Hospital, FIN-90221 Oulu, Finland, ${ }^{5}$ Department of Biology, Boston College, Boston, Massachusetts 02467, ${ }^{6}$ A. I. Virtanen Institute, University of \\ Eastern Finland, Kuopio, and ${ }^{7}$ Department of Neurology, Kuopio University Hospital, FIN-70211 Kuopio, Finland
}

\begin{abstract}
Although the Schwann cell basement membrane (BM) is required for normal Schwann cell terminal differentiation, the role of BMassociated collagens in peripheral nerve maturation is poorly understood. Collagen XV is a BM zone component strongly expressed in peripheral nerves, and we show that its absence in mice leads to loosely packed axons in C-fibers and polyaxonal myelination. The simultaneous lack of collagen XV and another peripheral nerve component affecting myelination, laminin $\alpha 4$, leads to severely impaired radial sorting and myelination, and the maturation of the nerve is permanently compromised, contrasting with the slow repair observed in $\mathrm{Lama4}^{-/-}$single knock-out mice. Moreover, the $\mathrm{Col15a1}^{-/-} ; \mathrm{Lama}^{-/-}$double knock-out (DKO) mice initially lack C-fibers and, even over 1 year of age have only a few, abnormal C-fibers. The $\mathrm{Lama}^{-/-}$knock-out results in motor and tactile sensory impairment, which is exacerbated by a simultaneous Col15a1 ${ }^{-/-}$knock-out, whereas sensitivity to heat-induced pain is increased in the DKO mice. Lack of collagen XV results in slower sensory nerve conduction, whereas the Lama4 ${ }^{-/-}$and DKO mice exhibit increased sensory nerve action potentials and decreased compound muscle action potentials; $\mathrm{x}$-ray diffraction revealed less mature myelin in the sciatic nerves of the latter than in controls. Ultrastructural analyses revealed changes in the Schwann cell BM in all three mutants, ranging from severe (DKO) to nearly normal $\left(\mathrm{Colls}^{-/-}\right)$. Collagen $\mathrm{XV}$ thus contributes to peripheral nerve maturation and C-fiber formation, and its simultaneous deletion from neural BM zones with laminin $\alpha 4$ leads to a DKO phenotype distinct from those of both single knock-outs.
\end{abstract}

\section{Introduction}

Peripheral nerve myelination is a highly coordinated process involving Schwann cell proliferation, radial sorting, and myelin assembly overlap (Martin and Webster, 1973; Webster et al., 1973; Stewart et al., 1993). Myelin increases the speed of neural conduction in axons, and defects in myelination cause a variety of congenital and acquired neurological disorders. A number of studies have demonstrated that myelination requires the interaction of Schwann cells with mole-

Received May 25, 2010; revised Aug. 16, 2010; accepted Aug. 22, 2010.

This work was supported by Research Council for Health of the Academy of Finland Grant 115237 and the Sigrid Jusélius Foundation. A.M.H. is a Research Fellow of the Academy of Finland. Work at Boston College (Boston, MA) was supported by Institutional Research Support Grants to (D.K.). We gratefully acknowledge the excellent technical contributions of Päivi Tuomaala, the staff of the Biocenter Oulu Electron Microscopy Laboratory (Oulu, Finland), and Kristina Kupsova (A. I. Virtanen Institute, Kuopio, Finland). We also thank Dr. Anna Domogatskaya (Karolinska Institute, Stockholm, Sweden) for kindly providing laminin-411 protein and antibodies used in the binding assay.

Correspondence should be addressed to Dr. Taina Pihlajaniemi, Oulu Center for Cell-Matrix Research, Biocenter Oulu, Department of Medical Biochemistry and Molecular Biology, Institute of Biomedicine, P.0. Box 5000, 90014 University of Oulu, Finland. E-mail: taina.pihlajaniemi@oulu.fi.

M. Hurskainen's present address: Department of Ophthalmology, Oulu University Hospital, FIN-90029 OYS, Finland. D01:10.1523/JNEUROSCI.2644-10.2010

Copyright $\odot 2010$ the authors $\quad 0270-6474 / 10 / 3014490-12 \$ 15.00 / 0$ cules in the basement membrane (BM), which assembles at the surface of axon-Schwann cell units (Moya et al., 1980; Carey and Todd, 1986; Eldridge et al., 1987). The main components of BMs are members of the collagen family of proteins, the laminins, nidogens, and perlecan (Yurchenco and Patton, 2009), and lack of the laminin $\alpha 4$ chain, a component of laminin-411, has been shown to lead to disturbances in radial sorting, delayed myelination, and ataxia, without affecting the BM (Wallquist et al., 2005; Yang et al., 2005). The roles of collagens in peripheral nerve development are essentially unexplored, with the exception of the $\alpha 4(\mathrm{~V})$ collagen chain, which has been shown to affect myelin assembly in vitro with no apparent effects on BM assembly (Chernousov et al., 2006).

Among the collagen family of proteins, the structurally homologous collagens XV and XVIII constitute the subgroup of multiplexins (multiple triple-helix domains and interruptions), and both are expressed in the BM zones of many tissues (Pihlajaniemi and Rehn, 1995). In view of the strong expression of collagen XV in peripheral nerves (Muona et al., 2002), we set out to investigate the possible contributions of this collagen to the development and functional properties of motor nerves. Like 
collagen XV, the laminin $\alpha 4$ chains are expressed in BMs of capillaries, muscle cells, and peripheral nerves (Petäjäniemi et al., 2002). Furthermore, similarities between the phenotypes of the collagen XV (Col15a1 $\left.{ }^{-/-}\right)$and laminin $\alpha 4\left(\right.$ Lama4 $\left.^{-/-}\right)$knockout mice prompted us to generate a Col15a1 ${ }^{-/-} ;$Lama $^{-/-}$double knock-out (DKO) mouse line to investigate possible functional or structural interactions between these two BM components. Col15a1 ${ }^{-/-}$mice suffer from progressive skeletal myopathy, cardiovascular defects, and degeneration of the capillaries (Eklund et al., 2001), whereas Lama4 ${ }^{-/-}$mice develop diffuse subcutaneous hemorrhages during the embryonic and neonatal periods and display abnormalities in their neuromuscular junctions (Patton et al., 2001; Thyboll et al., 2002). Moreover, Lama $^{-/-}$mice exhibit delayed myelination of the sciatic nerves and impaired motor functions, whereas myelination and axonal development in the CNS is normal (Wallquist et al., 2005; Yang et al., 2005). We show here that collagen XV is involved in mouse peripheral nerve maturation and in the formation of C-fibers. We also report $\mathrm{BM}$ zone alterations in the absence of laminin $\alpha 4$, which are more pronounced when collagen XV is also absent. We find that a simultaneous lack of collagen XV and laminin $\alpha 4$ leads to permanent defects in radial sorting and myelination and to more severe motor dysfunction and alterations in nerve physiology than in the corresponding single knock-out mice.

\section{Materials and Methods}

Animal models. The generation of the collagen XV $\left(\mathrm{Coll5a1}^{-/-}\right)$null and laminin $\alpha 4$ (Lama4 $^{-/-}$) null mice has been described previously (Eklund et al., 2001; Thyboll et al., 2002). The Col15a1 ${ }^{-/-}$mice were born in a Mendelian ratio, were fertile, and had a normal lifespan (Eklund et al., 2001). The Lama4 ${ }^{-/-}$mice were also born in a Mendelian ratio, but the homozygote mice were $10 \%$ smaller than controls and their mortality increased during the first 2 postnatal days because of hemorrhages. After the perinatal period, the lifespan was normal and the mice were fertile (Eklund et al., 2001; Thyboll et al., 2002). Both null mouse lines were backcrossed into a C57BL/ 6 background before crossbreeding to generate the compound Col15a1 ${ }^{-/-} ; \mathrm{Lama4}^{-/-}$line. The DKO mice were bred in a C57BL/6 background, and wild-type (WT) C57BL/6 mice were used as controls. All the animal experiments were approved by the Animal Care and Use Committee of the University of Oulu (Oulu, Finland). The permissions for the electrophysiological studies were 117/2002, 090/2007, and 104/2004.

Samples for light microscopy and ultrastructural analysis. The sciatic nerves from WT and mutant female and male mice aged 3, 5, 10, and $15 \mathrm{~d}$ and 1,2 , and 14 months were fixed in $1 \%$ glutaraldehyde and $4 \%$ formaldehyde in $0.1 \mathrm{~m}$ phosphate buffer, $\mathrm{pH}$ 7.4, for $5 \mathrm{~min}$ in situ, after which the nerves were removed. Fixation was continued for a total of $12 \mathrm{~h}$, after which the nerves were postfixed in $1 \%$ osmium tetroxide, dehydrated in acetone, and embedded in Epon Embed 812 (Electron Microscopy Sciences). One micrometer sections were stained with toluidine blue for histological analysis, and $80 \mathrm{~nm}$ sections were cut with a Leica EM UC6 ultramicrotome and examined in a Philips CM100 transmission electron microscope.

Antibodies. The primary antibodies and their respective dilutions were as follows: an affinity-purified rabbit polyclonal antibody against mouse collagen XV, at 1:50 (Muona et al., 2002); a rabbit anti-mouse antibody against collagen IV, at 1:300 (Millipore Bioscience Research Reagents); a rat monoclonal antibody against the human and mouse laminin $\gamma 1$ chains, at 1:50 (Millipore Bioscience Research Reagents); a rat monoclonal antibody against the mouse laminin $\beta 1$ chain, at 1:50 (Millipore Bioscience Research Reagents); a mouse monoclonal antibody against mouse dystroglycan, at 1:10 (Millipore Bioscience Research Reagents); a mouse monoclonal antibody against human and mouse $\beta 1$ integrins, at 1:50 (Santa Cruz Biotechnology); and a rat monoclonal antibody against mouse Ki67, at 1:50 (Dako).
Fluorescence microscopy. Nerves from 7-d-old, 1-month-old, and 2-month-old female and male mice were frozen on dry ice and cut into 5 $\mu \mathrm{m}$ sections on SuperFrost Plus glass slides (Menzel Gläser), which were then fixed in acetone or precooled ethanol for $10 \mathrm{~min}$ at $-20^{\circ} \mathrm{C}$. Sections for immunofluorescence staining were pretreated at room temperature with $1 \%$ BSA in PBS, $\mathrm{pH} 7.2$, and incubated overnight with a primary antibody diluted with $1 \%$ BSA in PBS, pH 7.2. The secondary antibodies were cyanine 3 -conjugated anti-rabbit (for $\beta 1$ integrin, collagen IV, and laminin $\beta 2$ ) and anti-rat (for laminin $\gamma 1$ and Ki67) antibodies purchased from Jackson ImmunoResearch. For dystroglycan staining, the Histomouse-Bulk kit (Invitrogen) was used after $10 \mathrm{~min}$ antigen retrieval using $10 \mathrm{~mm}$ citrate buffer $(\mathrm{pH} 6.0+0.05 \%$ Tween 20). The same antigen retrieval method was used for Ki67 staining. Fluorescent images were collected with a CellM Olympus microscope (Olympus Life Science Europe).

Immunoelectron microscopy (IEM). Sciatic nerves from 3-month-old WT and Lama $^{-1-}$ male mice were fixed in $4 \%$ paraformaldehyde in 0.1 $\mathrm{M}$ phosphate buffer with $2.5 \%$ sucrose, $\mathrm{pH} 7.4$, for $2 \mathrm{~h}$. Small tissue pieces were immersed in $2.3 \mathrm{M}$ sucrose and frozen in liquid nitrogen, and thin cryosections were cut with a Leica Ultracut UCT microtome. Sections for immunolabeling were first incubated in $0.05 \mathrm{~m}$ glycine in PBS, followed by incubation in $5 \%$ BSA with $0.1 \%$ cold-water fish skin gelatin (Aurion) in PBS. Antibodies and gold conjugate were diluted in $0.1 \%$ BSA-C (Aurion) in PBS. All washes were performed in $0.1 \%$ BSA-C in PBS. The sections were then incubated with antibody to collagen IV or collagen XV for $60 \mathrm{~min}$, followed by protein A-gold complex (size, $10 \mathrm{~nm}$ ) for $30 \mathrm{~min}$. For collagen XV staining, the grids were preincubated in chondroitinase $\mathrm{ABC}$ (Sigma-Aldrich) at a concentration of $0.02 \mathrm{U} / \mu \mathrm{l}$ for $45 \mathrm{~min}$. The controls were prepared by performing the labeling procedure without primary antibody. The sections were embedded in methylcellulose and examined as described above.

Solid-phase assay. Interaction of collagen XV with laminin-411 was tested in an ELISA. Ninety-six-well plates (Maxisorb) were coated for $2 \mathrm{~h}$ at room temperature with recombinant collagen XV (Hurskainen et al., 2010) at a concentration of $25 \mu \mathrm{g} / \mathrm{ml}$ in PBS with $\mathrm{CaCl}_{2}$. Wells were washed and blocked with 5\% milk-PBS. Recombinant laminin-411, consisting of laminin $\alpha 4 \beta 1 \gamma 1$ chains (a gift from A. Domogatskaya and K. Tryggvason, Karolinska Institutet, Stockholm, Sweden) at $40 \mu \mathrm{g} / \mathrm{ml}$ in PBS, was added to the washed wells and incubated overnight at $4^{\circ} \mathrm{C}$. After washing with PBS, laminin-411 was detected with anti-laminin $\beta 1$ or anti-laminin $\gamma 1$ monoclonal antibodies (gifts from A. Domogatskaya and K. Tryggvason), followed by incubation with secondary HRP antimouse antibodies and tetramethylbenzidine as a substrate. Optical density was measured $450 \mathrm{~nm}$ with a Victor Multilabel Counter.

Morphological analysis. Images from sciatic nerves were taken with an Olympus DP 50 microscope digital camera system and Analysis application. The measurements were made with MCID Core software (version 7.0, revision 2.0; GE Healthcare Niagara). The g-ratio (axon diameter/ total fiber diameter) of all axons was measured in three equivalent $100 \times$ $100 \mu \mathrm{m}$ areas from each nerve $(299-451$ axons per genotype in total, $n=$ 3 mice per genotype). For Student's $t$ test, all measurements were used as sample. The proliferation was measured from three different sections per nerve, two nerves per mouse $[n=5$ per genotype at postnatal day 7 (P7) and $n=3-4$ per genotype in 1 -month-old mice]. Two $40 \times$ power fields were imaged per section, and all Ki67-positive cells within the nerve (excluding perineural cells) were counted using NIH ImageJ software.

$X$-ray diffraction analysis. Nerves from 2-month-old (female and male) WT and mutant mice were prepared by immersion in $2 \%$ glutaraldehyde in $0.12 \mathrm{M}$ phosphate buffer at $\mathrm{pH} 7.4$ and inserted into $0.7 \mathrm{~mm}$ quartz capillary tubes (Charles Supper Co.) with medium. The tubes were sealed at both ends with wax and nail varnish. In addition to analyzing the sciatic nerves, in which genotype effects were expected, the optic nerves were examined as internal controls for the intrinsic variability of the measurements; no genotype effect is expected in the optic nerves because the fibers have no BM, and, although collagen XV and laminin $\alpha 4$ chain are expressed in the developing CNS, both are expressed only at low amounts in the adult brain (Muona et al., 2002; Lathia et al., 2007). The nerves from two animals of each genotype were subjected to "blind analysis," whereby the analyst had no previous knowl- 
edge of the corresponding genotypes. Diffraction readings were diffracted from both the proximal and distal segments of each pair of nerves dissected from each animal, yielding four measurements from a single animal of each genotype. Diffraction experiments were performed as detailed previously (Avila et al., 2005), with experiments using nickelfiltered, single-mirror focused $\mathrm{CuK} \alpha$ radiation from a fine-line source on a $3.0 \mathrm{~kW}$ Rigaku x-ray generator (Rigaku/MSC) operated at $40 \mathrm{kV}$ by 14 $\mathrm{mA}$. In typical experiments, the $\mathrm{x}$-ray diffraction patterns were recorded for $2 \mathrm{~h}$ using a linear position-sensitive detector (Molecular Metrology). Silver behenate powder was used to calibrate the specimen-to-film distance (Blanton et al., 1995). The diffracted intensity was analyzed using PeakFit (Jandel Scientific). Briefly, the peaks above the background were fitted to Gaussian or Pearson type IV distributions, yielding integral areas $I(h)$ and integral widths $w(h)$ for each reflection of order $h$. The myelin period $(d)$ was calculated from the positions of the reflections, which were typically the second-fifth orders, with a weak sixth order sometimes visible. The proportion of multilamellar myelin $[M /(M+B)]$ was expressed as the integrated intensity $M$ above the background divided by the total integrated intensity $M+B$, where $B$ was the background scatter as described previously (Avila et al., 2005). Normalizing the myelin diffraction in this manner minimizes the effects of different nerve thicknesses and any fluctuations in the output of the $\mathrm{x}$-ray tube.

Electrophysiological measurements. Nerve conduction velocity (NCV) and repetitive stimulation studies for the evaluation of peripheral nerve function and neuromuscular transmission were performed on 3-monthold male WT and mutant mice (7-11 mice per genotype). The recording techniques were adapted from those described by Stanley (1981), and the principles for the repetitive stimulation studies were adapted from those of Kimura (2001). Motor (MCV) and sensory (SCV) nerve conduction velocities and compound muscle (CMAP) and sensory nerve (SNAP) action potentials were determined, and $F$ latencies were measured. The animals were anesthetized with 30 and $2.5 \mathrm{mg} / \mathrm{kg}$ ketamine and xylazine, respectively, to prevent discomfort. Body temperature was monitored with a dermal temperature probe and maintained at $32^{\circ} \mathrm{C}$ with a warming lamp. Disposable platinum subdermal EEG electrodes (Nicolet) of 12 $\mathrm{mm}$ length and $0.4 \mathrm{~mm}$ diameter were used for the recording and stimulation. Surface electrodes were used for the repetitive stimulation studies. All the NCV studies were performed with a Keypoint Portable device (Medtronic A/S).

The compound muscle action potentials for the sciatic-tibial MCV studies were recorded from the plantar flexor muscles. Surface recording electrodes were placed in the skin above the plantar muscles of the foot, and a reference electrode was placed distally into the footpad. A surface electrode wrapped around the tail served as a ground electrode. Square pulses of fixed duration $(0.04 \mathrm{~ms})$ were used to stimulate the nerves. Supramaximal stimulation was given to obtain the maximum response. Latency was measured from the initial onset to the maximum negative peak and CMAP from peak to peak. The tibial nerve was stimulated at the sciatic notch and at the ankle. MCV was calculated as the distance divided by the difference between the proximal and distal latencies. $F$ latency was determined by stimulation at the ankle, and tail motor latency by stimulating the tail distally and making the recording proximally with an interelectrode distance of $3 \mathrm{~cm}$. Latency was measured from the initial onset to the maximum negative peak.

Tail sensory NCV and SNAP were determined by stimulation proximally along the tail using an inter-electrode distance of $3 \mathrm{~cm}$. Latency was measured from the initial onset to the maximum negative peak. The electrophysiological data were analyzed using the Statistical Package for the Social Sciences SPSS (version 13; SPSS Inc.).

Behavioral analysis. At 3-5 months of age, male mice underwent an extensive neurological test battery. Gait and motor coordination was assessed with round beam, rotarod, and beam-walking tests. The round beam test was performed as described by Voikar et al. (2001). The mouse was placed halfway along a horizontal round beam $(120 \mathrm{~cm}$ length, $2 \mathrm{~cm}$ diameter) raised $50 \mathrm{~cm}$ above the table level. The beam was covered with laboratory tape and $10 \mathrm{~cm}$ sections were marked. The retention time and the number of sections crossed on the beam in 3 min were measured for each mouse. The test was performed once per mouse, using 8-14 mice per genotype. The other neurological tests were conducted on a second group of mice, six mice per genotype. The Rota-Rod apparatus (Ugo Basile) was used to test motor coordination. In this rotarod test, the mouse is placed on a round $\operatorname{rod}(2 \mathrm{~cm}$ in diameter), the rotation of which gradually increased from 5 to $19 \mathrm{rpm}$. The latency to fall off from the rotating beam was recorded up until an 8 min cutoff time. The mouse was adapted to the test by first giving it $30 \mathrm{~s}$ to stay on a stationary rod and an additional $30 \mathrm{~s}$ at the minimum rotation speed. Beam walking was conducted on a horizontal, rectangular wooden beam, elevated $40 \mathrm{~cm}$ above floor level, that extended between on open start platform and a closed goal box that provided a hideaway in a well-lit room. The beam was $1 \mathrm{~m}$ long and consisted of four $25 \mathrm{~cm}$ continuous sections that became narrower and narrower $(3.5,2.5,1.5$, and $0.5 \mathrm{~cm})$. Each mouse got two training sessions on $2 \mathrm{~d}$ and a separate test session after a weekend. The time to cross the beam and the number of hindlimb slips were recorded.

Hindlimb reflexes were tested on the top of the home cage. Each test was repeated three times. Lift extension reflex was tested by lifting the mouse by the tail while it holds onto the cage grid with its forepaws. The test was scored as follows: 0 , no extension; 1 , occasional extension of one limb but not of the toes; 2 , occasional extension of both limbs but not of the toes; 3 , repeated extension of both limbs but not of the toes; 4 , repeatable full extension of both limbs and toes bilaterally. Descent extension reflex was tested by lowering the rear body by the tail toward the cage top and was scored as follows: 0 , no anticipatory extension; 1 , limb extension only one-third of the time and when touching the grid; 2 limb extension two-thirds of the time but late; 3 , limb extension each time but late; 4 , limb extension always before touching the grid. Both extension reflexes thus test the postural sense and were therefore averaged for a combined extension score. Grasping reflex was tested by gently touching the sole of one hindpaw at a time and then both together with a wooden stick while the mouse was suspended by the tail. The test was scored as follows: 0 , no grasping; 1 , weak and occasional grasping by one paw; 2 , repeated grasping but only weakly and with one paw; 3 , repeated grasping with both paws but weakly; 4, strong grasping with both paws. Grasping reflex thus depends on the cutaneous sense.

To test tactile threshold on the hindpaw, we used custom-made von Fray hairs. Monofilaments of different thickness and length $(3-7 \mathrm{~cm})$ were glued on a wooden spatula $(1 \times 15 \mathrm{~cm})$. The filaments were calibrated with a laboratory analysis scale to correspond to weights of 2.0, $2.8,3.2,3.8,4.3,4.7,5.5,6.2$, and $7.0 \mathrm{~g}$. The mouse was placed in an upside-down cage elevated $20 \mathrm{~cm}$ above the table top. The mouse stood on a $1 \times 1 \mathrm{~cm}$ grid made of $1 \mathrm{~mm}$ wire. The mouse was allowed to adjust to the test environment for $30 \mathrm{~min}$ before the test. Each filament was tested in ascending order until the mouse no longer reacted to touch. The threshold was then reinvestigated in descending order of filament stiffness. Pain threshold was tested on a hotplate with a surface temperature of $45^{\circ} \mathrm{C}$. The time to lick a paw was recorded until a cutoff time of $60 \mathrm{~s}$. Each mouse was tested three times, with $1 \mathrm{~h}$ between each test time. Exploratory activity and anxiety was tested in an elevated plus maze. The maze is shaped like a plus sign and consists of a square platform $(5 \times 5$ $\mathrm{cm})$ and four arms $(30 \times 5 \mathrm{~cm}$, two open and two closed). In dim ambient lighting, each mouse was placed on the center platform facing an open arm and allowed to explore the maze for $5 \mathrm{~min}$. The percentage of total time spent in the open arms and the total number of arm transitions were analyzed. Only those mice making more than four transitions between arms were included in the open/closed arm preference analysis. Anxiety in the form of object neophobia was tested by placing nine glass marbles ( $1 \mathrm{~cm}$ diameter) in the mouse home cage overnight and counting the number of marbles covered with bedding next morning.

Statistics. The electrophysiological data were analyzed using the Statistical Package for the Social Sciences SPSS (version 13; SPSS Inc.). The behavioral tests were analyzed using the Kruskal-Wallis nonparametric test between the four genotypes, followed by the Mann-Whitney $U$ test post hoc to compare each mutant line with the WT control. Statistical significance was set at $p<0.05$. Student's $t$ test was used for the analysis of the round beam test and morphological measurements. 

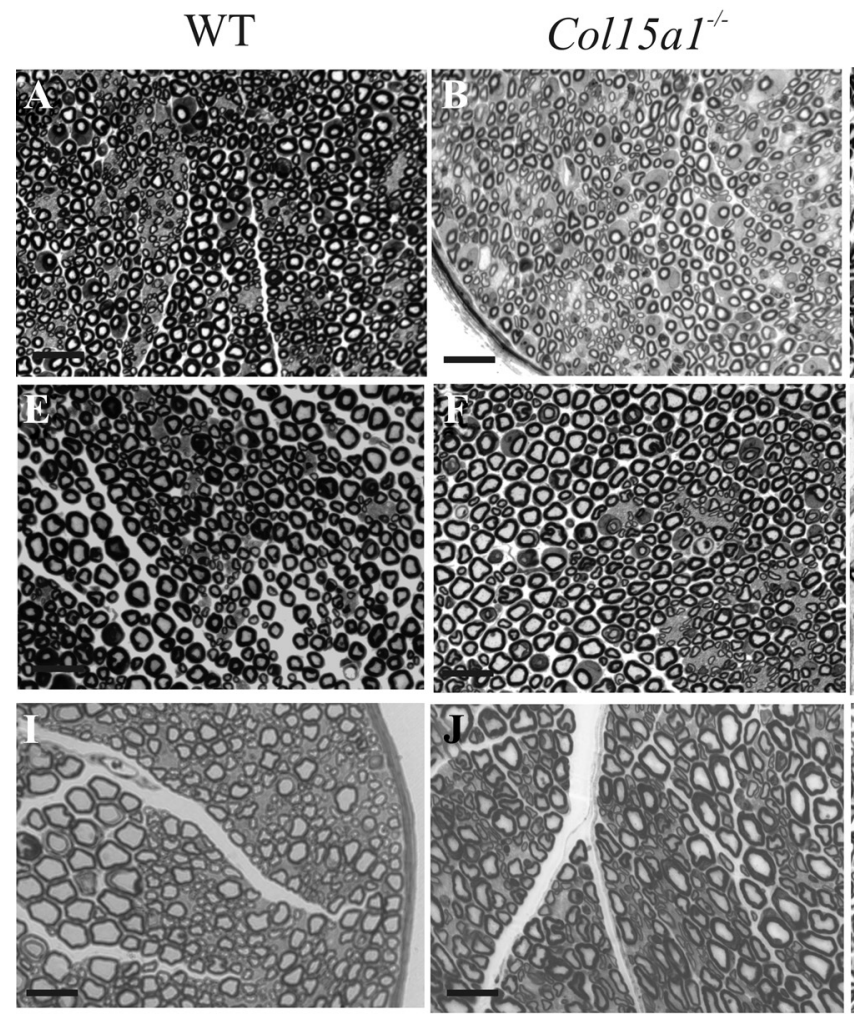

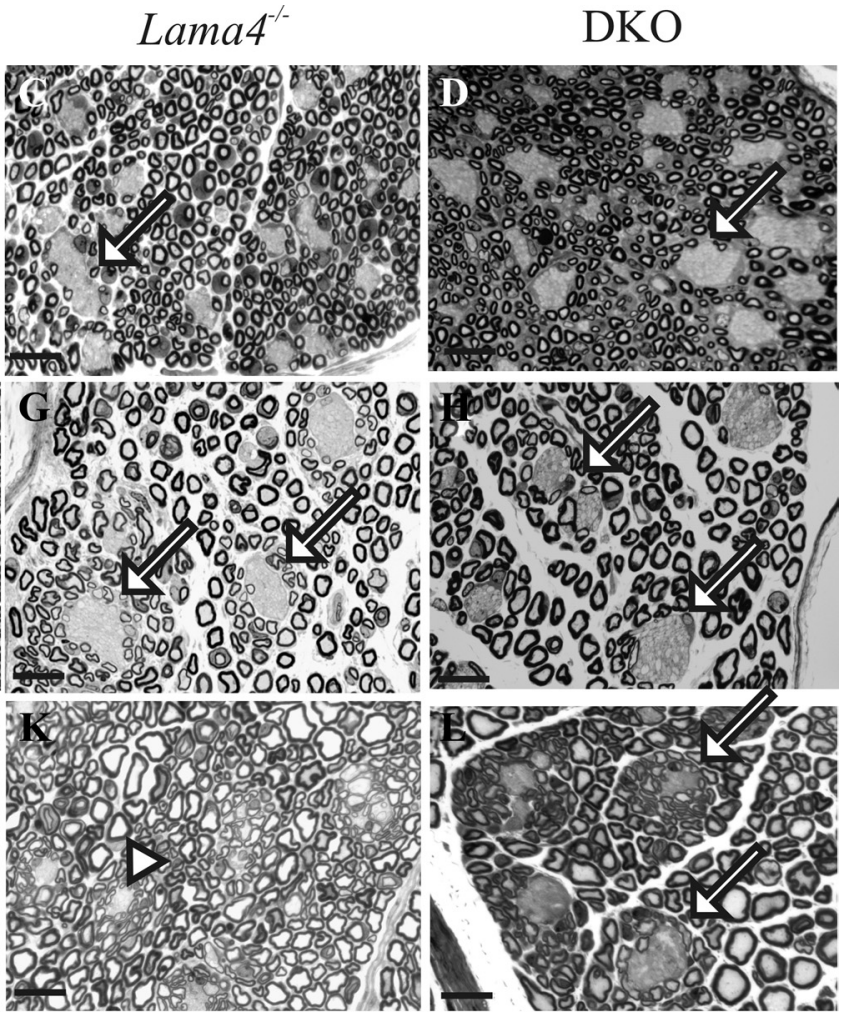

Scalebar $20 \mu \mathrm{m}$

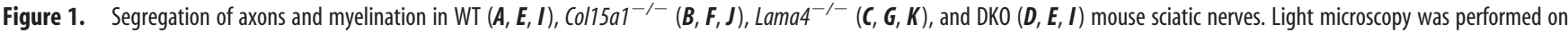
1-month-old $(\boldsymbol{A}-\boldsymbol{D})$, 2-month-old $(\boldsymbol{E}-\boldsymbol{H})$, and 14-month-old $(\boldsymbol{I}-\boldsymbol{L})$ mice. Axon segregation and myelination occurred in the $\mathrm{Col}_{15} \mathrm{I}^{-1-}$ mice in the same manner as in the WT but were retarded in the Lama4 ${ }^{-1-}$ mice, as witnessed by the occurrence of numerous nonsegregated axon bundles (arrows in $\mathbf{C}$, G). These bundles had essentially disappeared by the age of 14 months, and instead many small, recently myelinated axons were seen (arrowhead in $\boldsymbol{K}$ ). In the DKO mice, the defect in segregation and myelination was not corrected with time, and nonsegregated axon bundles were seen at all ages (arrows in $\boldsymbol{D}, \boldsymbol{H}, \boldsymbol{I}$ ). Scale bar, $20 \mu \mathrm{m}$.

\section{Results}

Simultaneous lack of collagen XV and laminin $\alpha 4$ leads to permanent defects in axonal segregation and myelination The single knock-out Col15a1 ${ }^{-\prime-}$ and Lama4 ${ }^{-/-}$mouse lines are viable (Eklund et al., 2001; Thyboll et al., 2002), and they were crossed here to generate a DKO line. The simultaneous lack of collagen XV and laminin $\alpha 4$ chains did not impair the viability of the mice. We then set out to study the roles of collagen XV and laminin $\alpha 4$ in the peripheral nerves (Fig. 1). Light microscopy of the sciatic nerves revealed similar, incompletely myelinated areas in the WT and mutant mice at 3-15 d of age (data not shown). These areas, representing embryonic axon bundles, disappeared by the age of 1 month in the WT and Col15a1 ${ }^{-/-}$mice, by which time the axons in the bundles were segregated and myelination was complete (Fig. 1A,B). Nonsegregated areas were conspicuous at the age of $15 \mathrm{~d}$ in the $\mathrm{Lama4}^{-/-}$mice and the DKO mice (data not shown), and nonsegregated axon bundles were still clearly visible in the former at 2 months of age (Fig. $1 G$ ) and in the latter at both 2 and 14 months of age (Fig. $1 H, L$ ). No significant differences in the number or size of the nonsegregated axon bundles were seen between the $\mathrm{Lama4}^{-/-}$mice and the DKO mice at the ages of $15 \mathrm{~d}, 1$ month, or 2 months, but the nonsegregated axon bundles were still abundant in the 14-month-old DKO mice (Fig. $1 \mathrm{~L}$ ), whereas those in the $L a m a 4^{-/-}$mice were somewhat smaller and surrounded by numerous small, recently myelinated axons (Fig. $1 \mathrm{~K}$ ).

Ultrastructural analysis confirmed the presence of large bundles of nonsegregated axons in the Lama4 ${ }^{-/-}$and DKO sciatic nerves (Fig. 2A,B) (see Fig. 6D), and closer examination of these structures indicated that Schwann cell processes segregate the axons in most, but not all, of the axon bundles of $\mathrm{Lama}^{-/-}$mice over 14 months old (Fig. 2A, inset), whereas in the case of the DKO mice, the axons remain nonsegregated in all the bundles (Fig. $2 B$, inset). Moreover, the nonsegregated bundles in the DKO mice are significantly larger than those in the Lama4 $^{-1-}$ mice $(p<0.0002)$ (Fig. $2 A, B)$ (see Fig. $6 D$ ). The simultaneous lack of collagen XV and the laminin $\alpha 4$ chain apparently does not allow for the repair or the slow progress of myelination that occurs when the laminin $\alpha 4$ chain alone is lacking.

Proliferation continues in adult $\mathrm{Lama4}^{-/-}$nerves but not in mice lacking both collagen XV and laminin $\alpha 4$

We used Ki67 staining to examine the Schwann cell proliferation rate in the developing and adult nerves. We found that there were significantly less proliferating cells in DKO and $\mathrm{Lama4}^{-/}$nerves at P7 compared with WT and Col15a1 ${ }^{-/-}$nerves $(p=0.02$ for WT vs DKO and $p=0.007$ for WT vs Lama4 ${ }^{-/}$) (Fig. 3A). In 1-month-old nerves, after the active myelination period has been completed in WT and Coll5a1 ${ }^{-1-}$ mice, very few proliferating cells could be seen in the nerve (perineural cells were not included in the calculations) (Fig. 3B). Lama4 ${ }^{-1-}$ nerves still contained many proliferating cells at this time point, indicating that proliferation started and continued later in these nerves (Fig. 3B). As in the WT nerves, Schwann cell proliferation was low in the 1 -month-old DKO nerves (Fig. $3 B$ ) ( $p=0.25$ for WT vs DKO). 

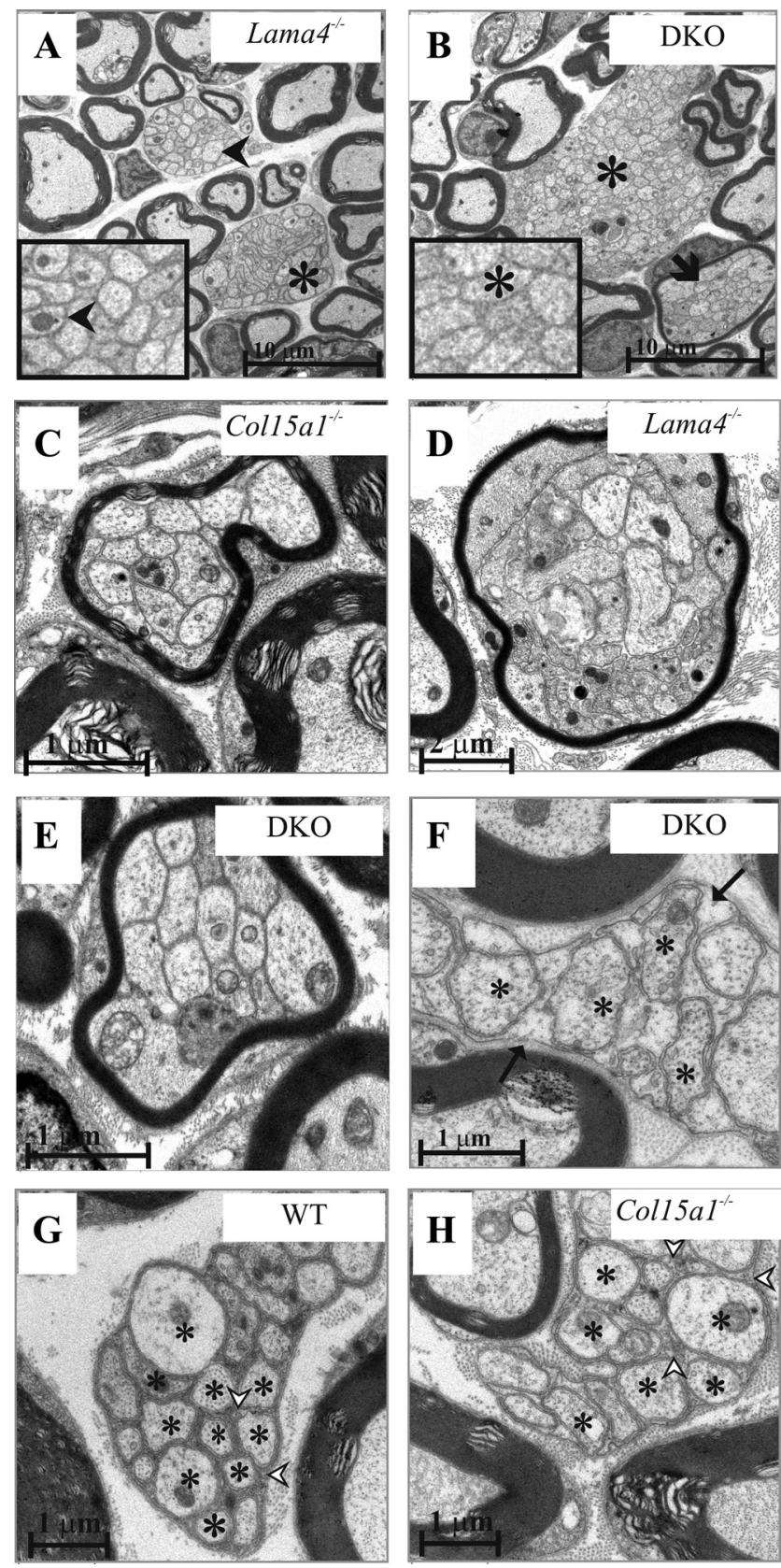

Figure 2. Nonsegregated axon bundles, polyaxonal myelination, and abnormal C-fibers in mutantmice. Ultrastructural analysis of sciatic nerves from WT, $\mathrm{Col}_{15 a 1^{-1-}}, \mathrm{Lama}^{-1-}$, and DKO mice. Large nonsegregated axon bundles were seen in the 14-month-old DKO mice, but only occasional small ones in the Lama4 ${ }^{-1-}$ mice of the same age. The arrowheads points to the Schwann cell cytoplasm that surrounds the segregated axons in a $\mathrm{Lama}^{-/-} \mathrm{C}$-fiber (inset in $\left.A\right)$. Asterisks mark the axons that are not segregated by Schwann cell extensions in $\boldsymbol{A}$ and $\boldsymbol{B}$ and inset in $\boldsymbol{B}$. Polyaxonal myelination was seen in the Col15a1 ${ }^{-/-}(\boldsymbol{C}) \mathrm{Lama4}^{-/-}(\boldsymbol{D})$, and DKO ( $\boldsymbol{E}$ and arrow in $\left.\boldsymbol{B}\right)$ mice in the form of thin myelin sheaths surrounding several nonsegregated axons. C-fibers are shown in $\boldsymbol{F}-\boldsymbol{H}$, with the asterisks denoting axons. The C-fiber axons in the 2-month-old WT mice were packed in a compact manner and the Schwann cell cytoplasm was electron dense (arrowheads in $\boldsymbol{G}$ ), whereas in the 2-month-old $\mathrm{Col}_{15 \mathrm{a} 1^{-1}}$ mice, the $\mathrm{C}$-fibers were disorganized and the Schwann cell cytoplasm was pale (arrowheads in $\boldsymbol{H}$ ). C-fibers were totally lacking in the 2 -month-old DKO mice and only a few were found at 14 months; the latter contained very translucent $S$ chwann cell cytoplasm (arrows in $\boldsymbol{F}$ ). Scale bars: $A, B, 10 \mu \mathrm{m} ; C, E-H, 1 \mu \mathrm{m} ; \mathbf{D}, 2 \mu \mathrm{m}$.

Polyaxonal myelination occurs in all these mutant mice In some cases, polyaxonal myelination (i.e., when numerous small axons are enclosed within a single, abnormally thin myelin sheath) was evident in 3-to 15-d-old WT mouse nerves (data not

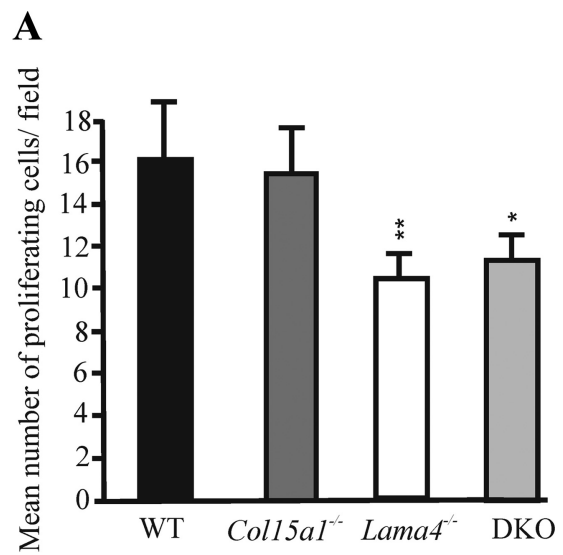

B

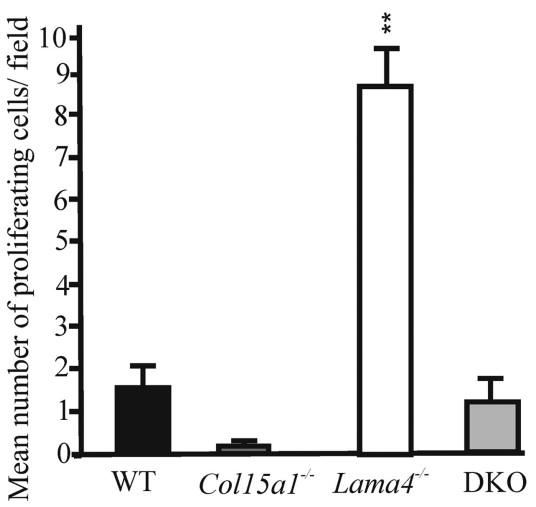

Figure 3. Proliferation in WT and mutant nerves. Ki67-positive cells per field at $P 7(\boldsymbol{A})$ and at the age of 1 month $(\boldsymbol{B})$. At P7 (A), Lama4 ${ }^{-1-}$ and DKO nerves have significantly fewer proliferating cells stained with Ki67 antibody compared with WT and Col15a ${ }^{-/-}$nerves ( $p=0.02$ WT vs DKO and $p=0.007$ WT vs Lama4 ${ }^{-1-}$ ). At 1 month of age ( $\boldsymbol{B}$ ), very few proliferating cells are seen in WT, Col15a1 ${ }^{-1-}$, and DKO, whereas proliferation is still going on in the $\mathrm{Lama4}^{-1-}$ nerves $\left(p=0.008\right.$ Lama4 $^{-1-}$ vs WT). ${ }^{*} p<0.05,{ }^{* *} p<0.01$. Values are expressed as mean \pm SEM number of proliferating cells per field.

shown). This is typical of an ongoing myelination process, and we found it to be corrected by remodeling during normal development in adult WT nerves (data not shown). In both single knockout lines and the DKO mutant mice, however, polyaxonal myelination was found not only in the young mice but also in adults (Fig. $2 C-E$ ). This is suggestive of a defective remodeling process and a diminished ability to establish a correct 1:1 axonSchwann cell relationship in the nerves of all three mutant mouse lines.

\section{Abnormalities in the formation of C-fibers}

Most axons in sensorimotor nerves such as the sciatic nerve are normally ensheathed by myelin-forming Schwann cells, but a specific set of axons, the C-fibers (representing the autonomic nerves and some of the sensory nerves), are surrounded by nonmyelinating Schwann cells, which form amyelin sheaths around the axons. The defect in axon segregation involved both myelinating and nonmyelinating Schwann cells. C-fibers could be distinguished in WT and Col15a1 ${ }^{-1-}$ sciatic nerves at $21 \mathrm{~d}$ after birth, whereas only a few correctly formed C-fibers were found in the Lama4 ${ }^{-1-}$ mice, but the latter also had a normal complement of $\mathrm{C}$-fibers at 14 months (data not shown). The 2-month-old DKO mice lacked C-fibers, and only a few were found at 14 months, all of which appeared abnormal (Fig. $2 F$ ). 

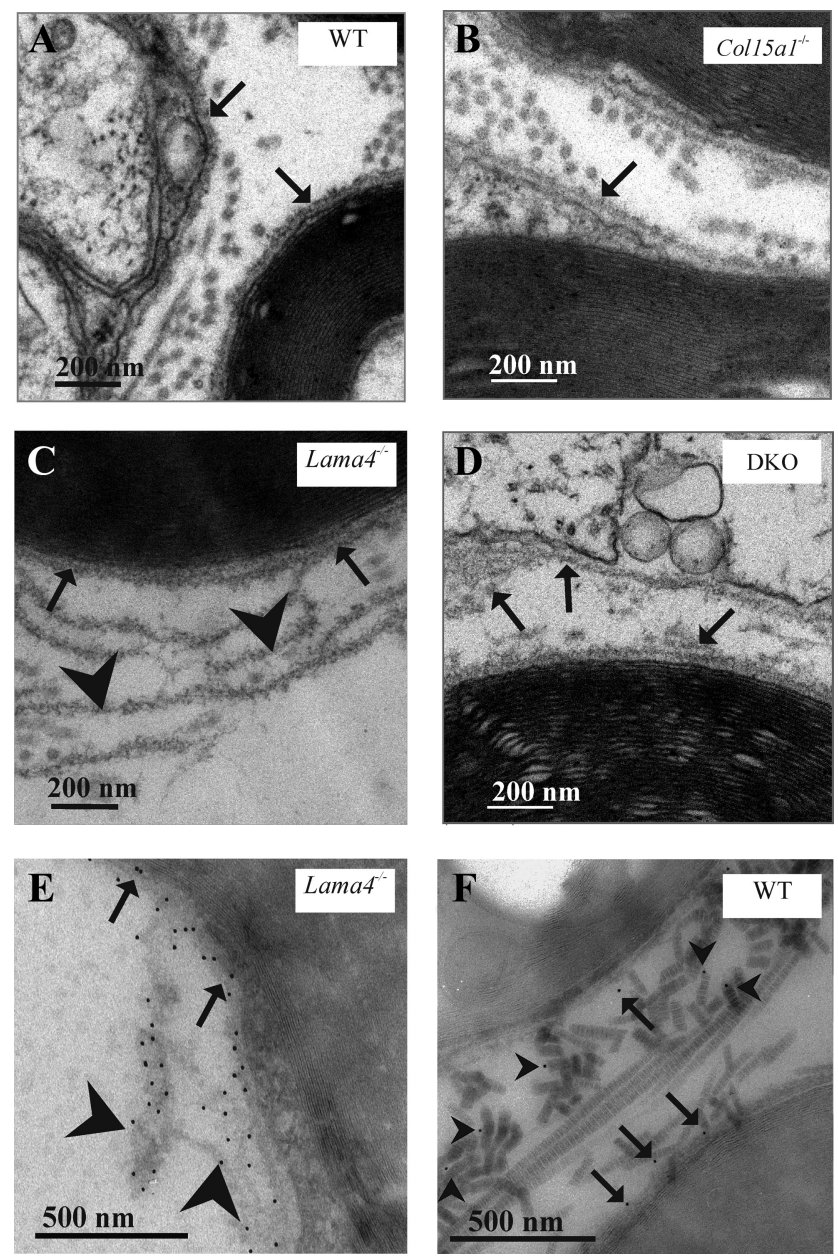

Figure 4. Altered BM structures in the mutant mice sciatic nerves and ultrastructural localization of collagen XV in the nerves. The BMs (arrows) in the WT mouse nerves were continuous

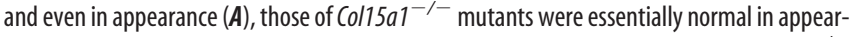
ance $(\boldsymbol{B})$ with the exception of occasional protrusions (arrow), and those of the Lama4 ${ }^{-1-}$ mouse nerves presented irregular BM-like folds (arrowheads) accumulating in the extracellular space (C). The BMs surrounding the Schwann cells of the DKO mice varied in thickness and presented fluffy protrusions $(\boldsymbol{D})$. Immunoelectron microscopy showed collagen IV labeling at the BM (arrows) and the irregular BM-like folds (arrowheads) present in the extracellular space of the Lama4 ${ }^{-/-}$mouse nerves $(\boldsymbol{E})$. Immunoelectron microscopy showed labeling of collagen $\mathrm{XV}$ (arrows) in the outer zone of the Schwann cell BM and in association with the adjacent fibrillar collagen (arrowheads) in WT $(\boldsymbol{F})$. Scale bar sizes are indicated in the images.

Although C-fibers could be found in normal amounts in the adult Col15a1 $1^{-/-}$nerves, the axons were more loosely packed than in the WT mice, and the Schwann cell cytoplasm was less electron dense (Fig. 2G,H).

\section{Disturbed BM formation}

The formation of the BM around the nonsegregated axon bundles, the myelinated axons, the nonmyelinating Schwann cells, and the polymyelinated axons was examined by electron microscopy in all of the mutant mice. As in the WT mice, the BM in the Col15a1 ${ }^{-/-}$mouse nerves was continuous and even in appearance, with the exception of occasional protrusions, suggesting a mild impairment of BM assembly (Fig. $4 A, B$ ). We frequently observed irregular, BM-like folds adjacent to a normal-looking BM (Fig. 4C) around both the nonsegregated axon bundles and the myelinated axons in the Lama4 ${ }^{-1-}$ mouse nerves, already at the age of 3 postnatal days. The irregular folds appeared to branch off from the BM and accumulated in the extracellular space; they were identified as BM material by collagen IV staining in IEM (Fig. 4E). This defect was still apparent at the ages of 2 months (Fig. 3C) and over 1 year (data not shown). The BM around the Schwann cells in the DKO mice (Fig. 4D) did not form irregular folds, but it varied in thickness and contained poorly organized BM-like material dispersed in the extracellular space (Fig. 4D).

Collagen XV has been detected previously in the endoneurium, perineurium, and epineurium in both developing and mature nerves (Muona et al., 2002) by immunofluorescence labeling. IEM revealed that collagen XV is localized to the outer zone of the Schwann cell BM in the sciatic nerve and in the adjacent fibrillar collagen matrix (Fig. 4F). Previous studies have shown that laminin $\alpha 4$ expression is upregulated in developing nerves (Patton et al., 1997, 1999; Nakagawa et al., 2001) and is expressed at least in the perineurium of adult mice (Nakagawa et al., 2001).

To test whether the loss of collagen XV and laminin $\alpha 4$ affects the composition of the endoneurial BMs, we stained cryosections of WT, Col15a1 ${ }^{-/-}$, Lama4 $^{-/-}$, and DKO sciatic nerves with antibodies for dystroglycan, laminin $\beta 1$, laminin $\gamma 1$, integrin $\beta 1$, and collagen IV. No differences were observed between the WT and mutant samples (supplemental Fig. 1, available at www. jneurosci.org as supplemental material). A previous study has reported an unaltered pattern of laminin $\beta 1, \alpha 1, \alpha 2$, and $\alpha 5$, entactin, perlecan, and agrin immunolabeling in the BM of the Lama4 $^{-/-}$sciatic nerves (Yang et al., 2005).

\section{Analysis of myelin structure by x-ray diffraction showed less myelin in DKO and Lama4 ${ }^{-/-}$mice}

$\mathrm{x}$-ray diffraction analysis confirmed that there was significantly less myelin in the DKO and Lama4 ${ }^{-/-}$mice, findings that correlated well with the presence of large nonsegregated axon bundles observed in the microscopic analyses. Diffraction from the fixed sciatic nerves showed strong $x$-ray scatter. The mean \pm SD myelin period in the WT mice was 197.8 $\pm 2.1 \AA$, and the proportion of the total scatter that was accounted for by the multilamellar myelin [calculated as $M /(M+B)$ ] was $0.21 \pm 0.05$ (Fig. 5). Optic nerves were used as controls, because these represent the CNS, which lacks the molecules studied here. Here, too, the $\mathrm{x}$-ray scatter was strong, with orders of 2-4 conspicuous. The mean period was $160.8 \pm 1.1 \AA$, and the proportion of the total scatter that was attributable to myelin was $0.15 \pm 0.04$ (Fig. 5). The differences in period and in the proportion of myelin between the sciatic and optic nerves taken as two groups were statistically significant $(p<0.0001)$. When the genotypes were correlated with the data, there was no statistically significant difference among the four groups concerning the optic nerves, but the genotypes of the sciatic nerves could be clearly distinguished, with a rank order from the strongest to the weakest pattern: $C_{0 l 15 a 1^{-/-}}>\mathrm{WT}>$ Lama4 $^{-1-}>$ DKO (Fig. 5).

The proportion of ordered myelin is consistent with previous measurements of other mouse sciatic nerves (Avila et al., 2004), but the values for the periods of WT myelin are nearly $10 \AA$ greater than those measured by us for other control nerves as a result of differences in either fixatives or mouse strains. Assessment of the myelin periodicity data with Student's $t$ test indicated significant differences in the sample means between the WT $(196.5 \AA)$ and DKO (199.5 $\AA)$ mice and between the WT and Lama4 $^{-/-}$mice $(198.5 \AA)(p<0.0002$ and $p<0.015$, respectively), whereas there was no significant difference between the WT and Col15a1 ${ }^{-/-}$mice (196.7 $\AA$ ). Comparing the proportions of myelin among the genotypes, we found that the only significant differences were between the WT (0.227) and DKO (0.157) 
groups $(p<0.0002)$ and the WT and Lama4 $^{-1-}(0.194)$ groups $(p<0.04)$.

Altered distribution of axon diameters, axon number, and g-ratios in mutant mouse nerves

The axon numbers were counted from 2-month-old nerves, and only the DKO mice showed a statistically significant decrease in the amount of axons ( $p=$ 0.0017) compared with WT (Fig. 6A). Lama4 $^{-/-}$mice tended to have fewer axons compared with WT, but the difference was not statistically significant $(p=$ 0.16 ) (Fig. 6A). The axon diameter distribution was slightly changed in the Col15a1 $1^{-/-}$nerves, which had more small axons, whereas the Lama4 $^{-1-}$ mice tended to have larger diameter axons compared with WT (Fig. 6B). DKO nerves had more very small axons $(<2$ $\mu \mathrm{m}$ diameter) than WT, but otherwise, there were fewer axons than normal in all the other axon size groups (Fig. 6B).

Myelin thickness, measured as the g-ratio, was lower in small-, medium-, and large-diameter axons of all mutant mouse lines (Fig. 6C). The mean g-ratios for WT nerves were $0.47,0.53$, and 0.57 (values corresponding to increasing axon diameter) compared with $0.51,0.56$, and 0.62 for Col15a1 ${ }^{-/-}$mice, 0.50, 0.59, and 0.63 for Lama4 ${ }^{-1-}$ mice, and 0.47, 0.59, and 0.63 for DKO mice; the differences relative to the WT were highly significant, except for the small-diameter axons of the DKO mice.

The areas occupied by nonsegregated axon bundles were measured in sciatic nerves from 2-month-old and 12- to 14month-old mice (Fig. 6D). In the 2-monthold Lama4 ${ }^{-/-}$nerves, the areas occupied by the nonsegregated bundles were larger compared with those of DKO mice sciatic nerves (Fig. 6D) $(p=0.046)$. In the older mice, the nonsegregated bundles remained large in the DKO mice, although they diminished in the $\mathrm{Lama4}^{-1-}$ nerves $(p<0.0002)$. We conclude that lack of collagen XV alone changed slightly the axon diameter distribution and, in particular, the g-ratio. Simultaneous lack of collagen XV and laminin $\alpha 4$ resulted in an impaired axonal segregation and in fewer myelinated axons.

\section{Electrophysiological measurements} reveal changes in motor nerve amplitudes and sensory conduction velocity

The mice were subjected to electrophysiological analysis to gain insight into the significance of the morphometric and be-
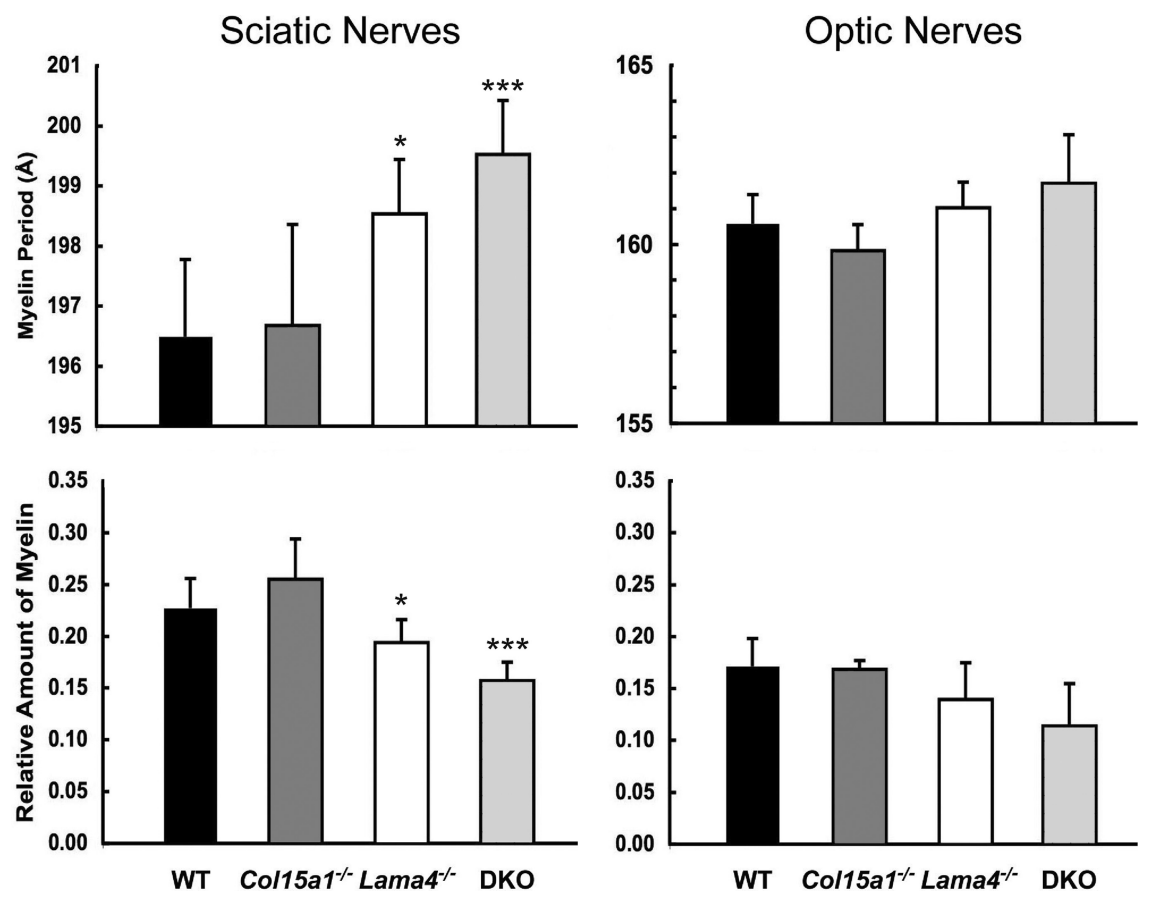

Figure 5. Less myelin and looser myelin periods in the $\mathrm{Lama}^{-/-}$and $\mathrm{Col} 15 \mathrm{a} 1^{-/-} ; \mathrm{Lama}^{-/-}$mouse sciatic nerves. The optic nerves served here as controls. The sciatic nerves showed significant differences in myelin periods between the WT (196.5 $\AA$ ) and the DKO (199.5 $\AA$ ) mice and between the WT and Lama4 ${ }^{-1-}$ mice $(198.5 \AA)$ at the age of 2 months $\left({ }^{* * *} p<0.0002\right.$ and ${ }^{*} p<$ 0.015 , respectively, in Student's $t$ test). This indicates that Lama $^{-/-}$and DKO sciatic nerves have larger myelin periods. Significant differences in the proportions of myelin were found between the WT $(0.227)$ and DKO (0.157) genotypes ( $\left.{ }^{* * *} p<0.0002\right)$ and between the WT and Lama4 $^{-1-}$ genotypes $(0.194)\left({ }^{*} p<0.04\right)$.
A

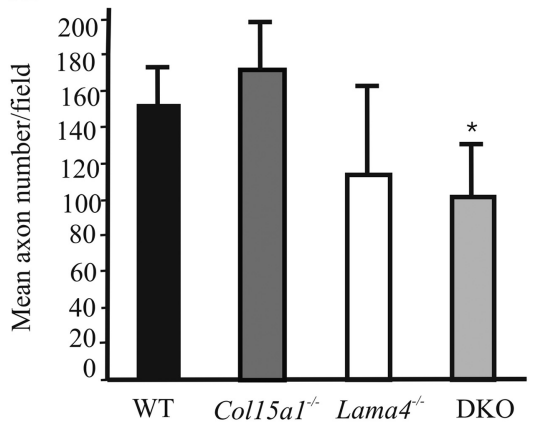

C

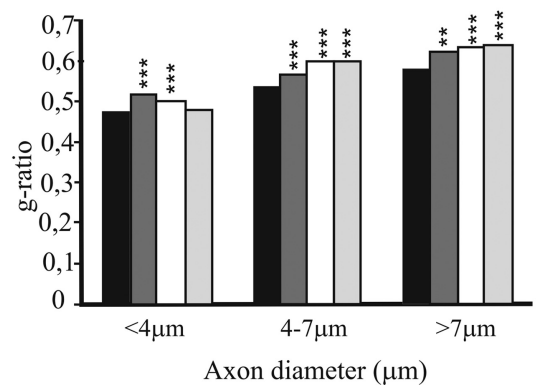

B

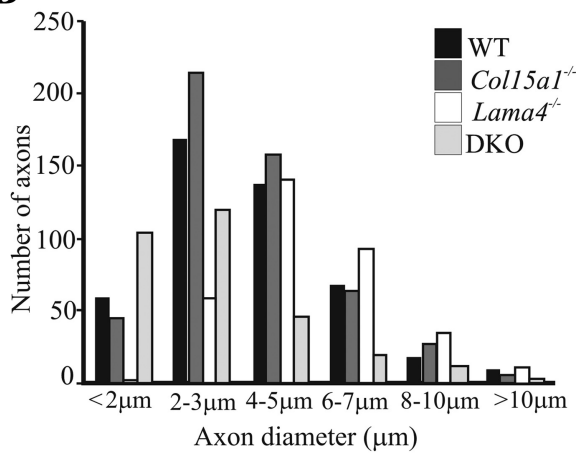

D

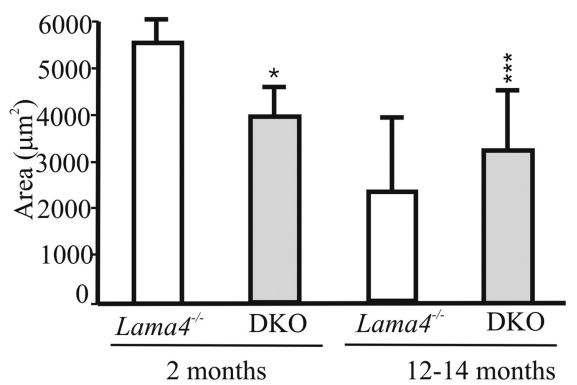

Figure 6. Assessment of axon diameter, axon number, g-ratios, and areas of nonsegregated axon bundles in sciatic nerves. $\boldsymbol{A}$, The number of axons counted per field. ${ }^{*} p=0.03$ denotes difference from WT. $\boldsymbol{B}$, Number of axons counted per field and grouped according to axon diameter. $\boldsymbol{C}$, Myelin thickness ( $\mathrm{g}$-ratio = axon diameter/total fiber diameter) measurements shown for different diameter axons. ${ }^{* *} p<0.01$ denotes difference from WT; ${ }^{* * *} p<0.001$ denotes difference from WT. $\boldsymbol{D}$, Areas occupied by nonsegregated axon bundles (measured from equivalent regions of the nerves) in 2-month-old and 12-to 14-month-old mice. ${ }^{*} p>0.046$ denotes difference from Lama4 ${ }^{-1-}$ nerves, ${ }^{* *} p<0.0002$ denotes difference from Lama4 ${ }^{-1-}$. Values are expressed as the mean \pm SD area. 
Table 1. Tibial motor nerve CMAPs

\begin{tabular}{|c|c|c|c|c|c|c|}
\hline \multirow[b]{2}{*}{ Genotype } & \multicolumn{2}{|l|}{ CMAP (mV) } & \multicolumn{2}{|l|}{$p$ (to WT) } & \multicolumn{2}{|c|}{$p$ (to DKO) } \\
\hline & CMAP $1 \pm S D$ & CMAP $2 \pm S D$ & CMAP 1 & CMAP 2 & CMAP 1 & CMAP 2 \\
\hline WT & $14.7 \pm 7.0$ & $17.7 \pm 8.4$ & & & & \\
\hline $\operatorname{Lam} \alpha 4^{-/-}$ & $5.6 \pm 4.2$ & $7.2 \pm 4.1$ & 0.002 & 0.006 & 0.386 & 0.272 \\
\hline $\mathrm{Col}_{15 a 1^{-/-}}$ & $11.4 \pm 8.8$ & $15.2 \pm 12.5$ & 0.396 & 0.63 & 0.045 & 0.047 \\
\hline DKO & $4.4 \pm 1.8$ & $5.3 \pm 3.4$ & 0.002 & 0.002 & & \\
\hline
\end{tabular}

CMAP 1, Mean compound action potential with stimulation at the sciatic notch; CMAP 2, mean compound action potential with stimulation at the ankle.

Table 2. Tail SNAP and tail SCV

\begin{tabular}{lllll}
\hline Genotype & SNAP $\pm S D(\mu \mathrm{V})$ & $p$ (to WT) & $S C V \pm S D(\mathrm{~m} / \mathrm{s})$ & $p$ (to WT) \\
\hline WT & $261 \pm 40$ & & $36.0 \pm 3.5$ & \\
${\text { Lam } \alpha 4^{-/-}}_{\text {Col15a1 }}^{-1-}$ & $328 \pm 91$ & 0.052 & $33.8 \pm 5.0$ & 0.277 \\
DK0 & $265 \pm 91$ & 0.909 & $28.7 \pm 5.4$ & 0.005 \\
\hline
\end{tabular}

There is no statistical difference between the SNAP of $\mathrm{Lama4}^{-1-}$ and DKO ( $p=0.429$ ).

havioral findings. Both the motor and sensory nerve conduction studies showed substantial differences between the genotypes. A marked reduction occurred in the CMAPs of the tibial nerve in both mutants lacking laminin $\alpha 4$, indicating that the number of normally functioning motor axons is reduced when laminin $\alpha 4$ is absent (Table 1). The tibial CMAP amplitudes in the WT mice were 14.7 and $17.7 \mathrm{mV}$ when stimulated at the sciatic notch and at the ankle, respectively, whereas those in the Lama4 ${ }^{-1-}$ mice were 5.62 and $7.22 \mathrm{mV}$, respectively, and those in the DKO mice 4.39 and $5.30 \mathrm{mV}$, respectively. Although the DKO mice showed a trend for less functioning motor axons compared with $\mathrm{Lama4}^{-/-}$ mice, the difference was not statistically significant ( $p=0.38$ and 0.27 for stimulations at the sciatic notch and ankle, respectively), probably because the Lama4 $4^{-/-}$and DKO mice were still morphologically similar at 3 months of age. The Col15a1 $1^{-/-}$mice showed no changes in tibial CMAP amplitudes (11.4 and 15.2 $\mathrm{mV}$ ) relative to the $\mathrm{WT}$ mice (Table 1 ). Motor nerve conduction velocity profiles were normal in all the mice (data not shown), and studies using repetitive stimulation also showed normal responses.

The sensory nerve action potential was increased in both the $\mathrm{Lama}^{-1-}$ and DKO mice relative to the WT mice, the values being 328,345 , and $261 \mu \mathrm{V}$, respectively (Table 2), but lack of laminin $\alpha 4$ had no significant effect on the SCV measured from the tail (Table 2). The SCV value was significantly lower in the Col15a1 $1^{-/-}$mice than in the WT, Lama4 ${ }^{-/-}$, or DKO mice (28.7, $36.0,33.8$, and $33.4 \mathrm{~m} / \mathrm{s}$, respectively), indicating that a lack of collagen XV alone results in poorer conduction in the sensory nerves (Table 2). The ultrastructure of the nodes of Ranvier (data not shown) was studied by transmission electron microscopy, but differences that would explain the poorer conduction in Col15a1 $1^{-/-}$sensory nerves were not observed.

\section{Impaired sensorimotor functions in the absence of laminin $\alpha \mathbf{4}$}

The tests for motor coordination and balance, involving proprioception and muscle strength, revealed impaired performance in the mutant mice in a graded manner. In the round beam test, all three mutants fell off the beam and were less active than their WT littermates. The performance was most severely compromised in DKO mice, followed by Lama4 ${ }^{-/-}$and Col15a1 $1^{-1-}$ mice (Table 3). Similar graded impairment was found in the rotarod test (Fig. $7 A$ ), in which DKO and Lama4 ${ }^{-1-}$ differed significantly from the WT littermates. In the beam-walking test, Lama4 ${ }^{-/-}$and DKO mice took longer to cross the beam (Table 3) and made more hindlimb slips (Fig. 7B).

The hindlimb reflexes were clearly impaired in both $\mathrm{Lama4}^{-1-}$ and DKO mice (supplemental movies, available at www.jneurosci.org as supplemental material). Intriguingly, $\mathrm{Lama}^{-/-}$and Col15a1 ${ }^{-/-}$genotypes appeared to have additive effects in extension reflexes that depend on postural sense (Fig. 7C), whereas Col15a1 $1^{-/-}$tended to alleviate the $\mathrm{Lama4}^{-/-}$genotype in grasping reflex that draws on cutaneous sensation (Fig. 7D). Conversely, both Lama4 ${ }^{-/-}$and DKO mice were impaired in their tactile sensory threshold as assessed by von Frey hairs (Fig. 7E). Only DKO mice exhibited a significantly enhanced sensitivity to heat pain in the hotplate test (Fig. $7 F$ ).

The observed motor impairment in $\mathrm{Lama4}^{-/-}$and DKO mice did not prevent them from moving around. No genotype differences were observed in exploratory movements between arms in the elevated plus-maze test (Table 3). Furthermore, a possible confounding effect of anxiety to sensorimotor test performance could be ruled out by similar scores of all genotypes in parameters measuring anxiety (Table 3 ).

\section{Discussion}

We show here that the physiological function of collagen XV, which is associated with most BMs, is not restricted to skeletal muscle and heart (Eklund et al., 2001) but also encompasses the peripheral nerves. The Coll5a1 ${ }^{-/-}$mouse nerves exhibit polyaxonal myelination and C-fibers with abnormal Schwann cell profiles, whereas the myelinated axons were normally segregated. Although a significantly lower sensory nerve conduction velocity was measured in the tails of the Col15a1 ${ }^{-/-}$mice relative to the WT, there was no effect on the tibial CMAP amplitudes. The Coll $\mathrm{al}^{-/-}$mice did suffer from motor impairment, however, as evidenced by falling, hindlimb slips, and hesitance to move on a beam in the behavioral tests. Taking into consideration the morphological findings and sensory deficits in behavioral tests, we suggest that the motility defect may have been caused by the multimodal afferent sensory pathway dysfunction observed here; ephaptic transmission between axons lacking Schwann cell ensheathment and the previously observed mild myopathy are also likely to be among contributing factors (Eklund et al., 2001).

Lack of laminin $\alpha 4$ is known to lead to disturbances in the segregation of axons and to polyaxonal myelination (Wallquist et al., 2005; Yang et al., 2005). We found that lack of both collagen $\mathrm{XV}$ and laminin $\alpha 4$ has a compound effect on the peripheral nerves. The distribution of axon diameters is altered in the absence of laminin $\alpha 4$, and this is even more prominent when both laminin $\alpha 4$ and collagen XV are lacking, possibly explaining the increased SNAP seen in the $\mathrm{Lama4}^{-1-}$ and DKO mice. It is also possible that the nonsegregated axon bundles affect the electrophysiological measurements and account for the increased SNAP. The marked reductions in tibial CMAP amplitudes in the Lam $\alpha 4^{-/-}$and DKO mice imply that the number of normally functioning motor axons was 
Table 3. Behavioral tests

\begin{tabular}{|c|c|c|c|c|}
\hline Test & WT & $\mathrm{Col}_{15 a 1^{-/-}}$ & $\operatorname{Lama4}^{-/-}$ & DKO \\
\hline Round beam $(n)$ & 13 & 9 & 8 & 14 \\
\hline Falls & 0 & $0.44 \pm 0.1^{*}$ & $1.0 \pm 0.3^{* *, \#}$ & $2.2 \pm 0.4^{* * *}$ \\
\hline Sections crossed & $61.9 \pm 2.6$ & $27.1 \pm 6.5^{* * *}$ & $28.6 \pm 7.0^{* * *, \#}$ & $15.6 \pm 2.8^{* * *}$ \\
\hline Description & Active & Less active & Trembling & Heavy trembling \\
\hline Beam walking $(n)$ & 6 & 6 & 6 & 6 \\
\hline Time to cross (s) & $3.2 \pm 0.5$ & $2.8 \pm 0.1$ & $5.9 \pm 0.4^{*}$ & $6.5 \pm 0.8^{\#}$ \\
\hline Plus maze $(n)$ & 6 & 6 & 6 & 6 \\
\hline Total arm visits & $12.3 \pm 2.1$ & $13.1 \pm 2.4$ & $17.5 \pm 1.1$ & $16.5 \pm 1.6$ \\
\hline Percentage time open arms & $34.1 \pm 5.6$ & $24.3 \pm 8.9$ & $12.5 \pm 3.3$ & $20.1 \pm 8.3$ \\
\hline Object neophobia $(n)$ & 6 & 6 & 6 & 6 \\
\hline Uncovered marbles & $6.7 \pm 1.0$ & $5.7 \pm 1.2$ & $6.5 \pm 0.9$ & $6.8 \pm 1.0$ \\
\hline
\end{tabular}

reduced when laminin $\alpha 4$ was absent. Performance in the behavioral tests was most severely compromised in the $\mathrm{DKO}$, with trembling on the beam, ataxia, and slipping of the hindlimbs, and this was apparently attributable to a more prominent delay in the axonal segregation and a more pronounced lack of $\mathrm{C}$-fibers relative to the Lam $\alpha 4^{-/-}$mice.

Laminin $\alpha 4$ is mainly expressed in immature, developing nerves (Patton et al., 1997; Nakagawa et al., 2001; Wallquist et al., 2002), which may account for the partial recovery of the axonal segregation observed in the $\mathrm{Lama}^{-/-}$mice over 1 year of age. Nonsegregated axons are prominent in both young and old DKO mice, signifying a permanent defect attributable to the absence of the normally constitutively expressed collagen XV. Moreover, it seems that a lack of the laminin $\alpha 4$ chain leads to retarded segregation of some axonal bundles, but once the segregation has taken place, the subsequent terminal differentiation appears to proceed normally. These findings may reflect the lower rate of postnatal Schwann cell proliferation in the $\mathrm{Lama}^{-/-}$and DKO nerves, whereas, at 1 month of age, proliferation persists in Lama4 ${ }^{-1-}$ but slows down considerably in the WT, Col15a1 ${ }^{-/-}$, and DKO nerves.

The delayed axonal segregation observed in the C-fibers of $\mathrm{Lama}^{-/-}$mice and the absence of segregation observed in those of the DKO mice indicate that the BM components, laminin $\alpha 4$ and collagen $\mathrm{XV}$, play essential roles in the segregation of the axons in the embryonic fiber bundles during C-fiber development. C-fiber function was tested with a hotplate test, and the adult Lama4 $^{-/-}$mice, showing that morphologically normal C-fibers did not differ significantly from the WT mice. We assumed that the Col15a1 ${ }^{-/-}$mice, having morphologically disorganized C-fibers, would show changes in the test; no difference was observed. However, the DKO mice, essentially lacking the Cfibers, exhibited enhanced sensitivity to heat pain. Based on our group).
A

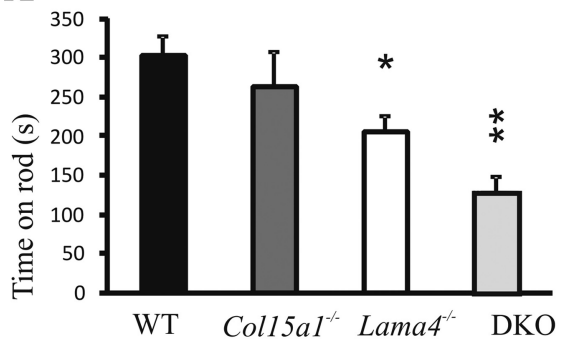

C

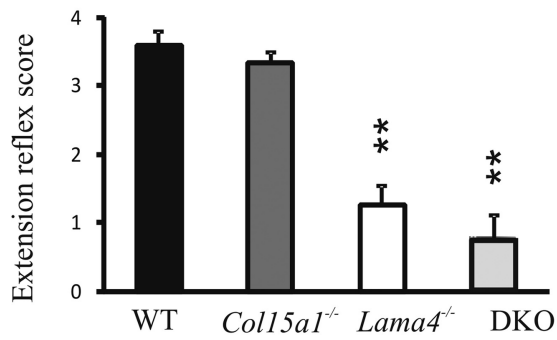

E

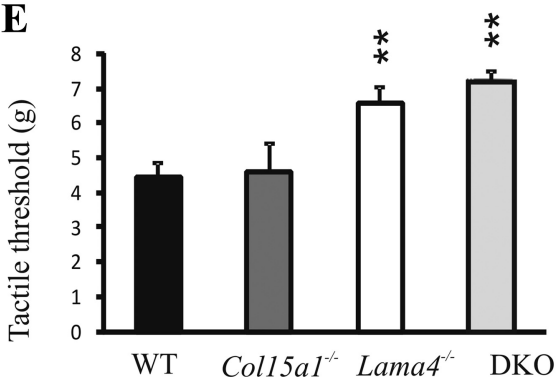

B

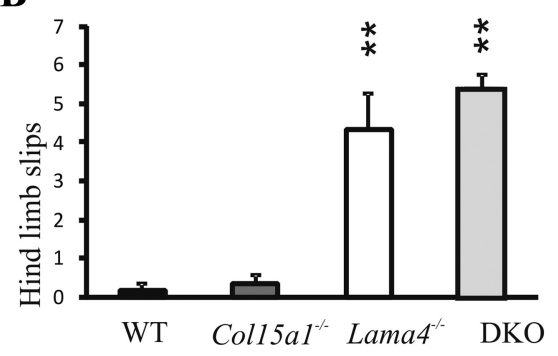

D

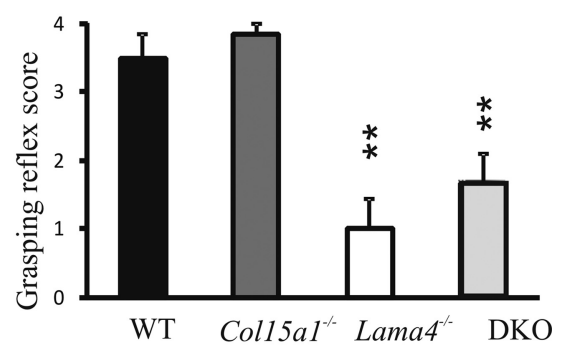

F

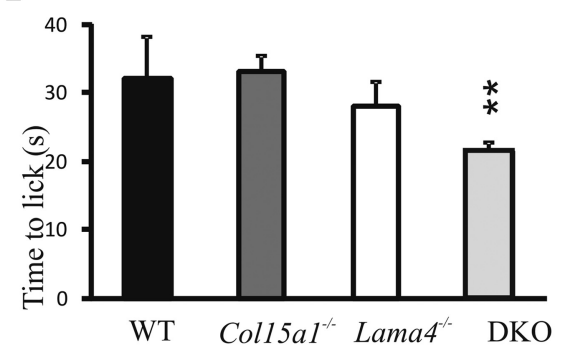

Figure 7. Behavioral tests for motor and sensory functions. $\boldsymbol{A}$, Rotarod test: $y$-axis indicates time to fall in seconds. Significant difference between the genotypes ( $\mathrm{df}=3, \chi^{2}=12.1, p=0.007$, Kruskal-Wallis test). $\boldsymbol{B}$, Number of hindlimb slips in the beam-walking test differs between the genotypes $\left(\chi^{2}=17.9, p<0.001\right)$. $\boldsymbol{C}$, Average score $(0-4)$ of lift extension and descent extension reflexes of hindlimbs: a high score indicates normal status. Significant difference between the genotypes $\left(\chi^{2}=18.2\right.$, $p<0.001)$. $\boldsymbol{D}$, Corresponding score for hindlimb grasping reflex $\left(\chi^{2}=14.2, p=0.003\right)$. , Tactile threshold as assessed by von Frey hairs. The $y$-axis indicates the ostensible weight of the filament on the surface in grams (score 8 indicates no reaction to $7.0 \mathrm{~g}$ filament). Significant difference between the genotypes $\left(\chi^{2}=13.9, p=0.003\right)$. $\boldsymbol{F}$, Time in seconds to lick a paw on the hotplate. Significant difference between the genotypes $\left(\chi^{2}=7.7, p=0.02\right) .{ }^{*} p<0.05$ denotes difference from WT; ${ }^{* *} p<0.01$ denotes difference from WT (except in $\boldsymbol{F}$ in which the comparison is with Col15a1 $1^{-/-}$mice attributable to a high variability in the WT

morphological analysis, C-fibers in the DKO mice are nonsegregated and embedded in large nonsegregated bundles; this could lead to the observed abnormal pain signal and allodynia in the mice. We were unable to detect an abnormal C-fiber phenotype in the functional 
Genotype WT

Time point

P5

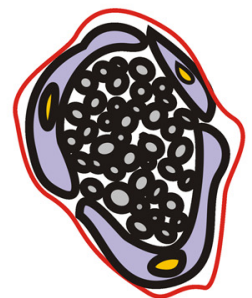

1 year

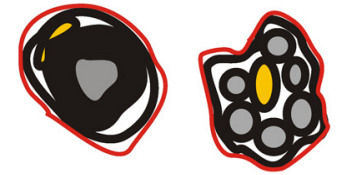

\section{Summary of findings}

BM:

Myelinated axons:

Polymyelinated axons:

Non-segregated

axon bundles:

C-fibers:

Normal
Yes
No
No
Normal

Col15a1 $^{-\alpha}$
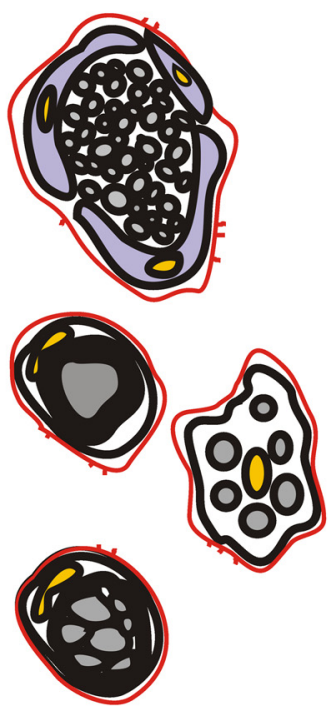

Occassional protrusions

Yes

Yes

No

Slightly disorganized
Lama4 $^{-1}$

DKO

Figure 8. Summary of findings in Col15a1 ${ }^{-1-}$, Lama4 ${ }^{-1-}$, and DKO sciatic nerves. At P5, the myelination process is ongoing in WT and mutant mice, and nerves of all genotypes contain nonsegregated axon bundles. The characteristic BM (drawn in red) defects are seen in all mutants already at P5. At the age of 1 year, WT mice show myelinated axons as well as $C$-fibers. Col15a 1 - /nerves show normally myelinated axons, polymyelinated axons, and disorganized C-fibers. Lama4 ${ }^{-1-}$ nerves contain normally myelinated axons, C-fibers, polymyelinated axons, and small nonsegregated axon bundles. Abnormal BM folds are accumulating in the extracellular space. DKO nerves contains normally myelinated axons but only a few and very abnormal-looking C-fibers, polymyelinated axons, and large, nonsegregated axon bundles. An irregular, partly broadened BM covers the Schwann cells.

tests performed with 3-month-old mice lacking only collagen XV, but a role of the latter in C-fiber development and/or function is suggested by the amplified phenotypic effect observed when laminin $\alpha 4$ is also lacking.

The persistence of polyaxonal myelination in the Col15a1 ${ }^{-/-}$, $\mathrm{Lama}^{-/-}$, and DKO mice points to a developmental failure that allows myelin to be formed around the axons before they are correctly segregated from each other. We observed occasional polyaxonal myelination in WT mice during the active myelination period (i.e., during the first month after birth) but never in mature nerves, indicating that this defect is normally corrected through remodeling, whereas it persists in mutant mice.

$\mathrm{x}$-ray diffraction was used to examine aldehyde-fixed sciatic nerves for small differences in period and/or myelin amounts. WT and Col15a1 ${ }^{-/-}$nerves had comparable myelin periods and extents of myelination, whereas the Lama4 $4^{-/-}$and DKO nerves had less myelin, which was also less. However, the g-ratio measurements revealed that myelin thickness, relative to axon diameter, was reduced in all three mutant lines.

The peripheral nerve BM in the Col15al ${ }^{-1-}$ mice was practically normal, with the exception of occasional protrusions. Analyses of human kidney, placenta, and colon tissues have shown that collagen XV is located in the outermost layer of the BM and in the adjacent fibrillar matrix (Amenta et al., 2005). Here, we demonstrate a similar localization of collagen XV in the peripheral nerves. Its normal presence at the BM-fibrillar matrix boundary could explain the essentially normal appearance of the
BMs themselves when collagen XV is absent. Conversely, laminin $\alpha 4$ is an integral constituent of BMs (Petäjäniemi et al., 2002; Wallquist et al., 2002), and, although the BM surrounding the Schwann cells in the Lama4 ${ }^{-/-}$mice has a normal, even appearance, we frequently observed collagen IV-positive folds, which seemed to have been shed from the BM. This is indicative of a structural defect caused by the deficiency in laminin $\alpha 4$. Because the BM defect is seen in the nerves of the Lama4 $^{-/-}$mice at ages ranging from $3 \mathrm{~d}$ to over 1 year, we suggest that laminin $\alpha 4$ continues to have a function even in mature nerves. The simultaneous lack of collagen XV and laminin $\alpha 4$ resulted in more marked effects, with the frequent occurrence of uneven BMs with areas of fluffy accumulations. However, we were unable to demonstrate a direct interaction between recombinant collagen XV and laminin-411 (consisting of $\alpha 4 \beta 1 \gamma 1$ chains) proteins in an ELISA (data not shown). Nevertheless, we cannot exclude the possibility that the glycosamino glycan chains present in authentic collagen XV (Hurskainen et al., 2010) could have a role in laminin binding.

The BM mediates changes in cell shape by means of receptor linkage to the Schwann cell cytoskeleton; Schwann cells are thus able to extend processes, ensheath axons, and form myelin (Fernandez-Valle et al., 1997). Dysmyelination has been proposed to derive from the disruption of Schwann cell BMs (Eldridge et al., 1989; Feltri et al., 2002), although myelination could occur in the absence of a BM in the spinal root of $\mathrm{dy}^{3 \mathrm{~K}} / \mathrm{dy}^{3 \mathrm{~K}}$ 
mice lacking laminin $\alpha 2$ (Nakagawa et al., 2001). Myelination also occurred in the spinal roots of dy2J/a4 null mice lacking both laminin $\alpha 2$ and $\alpha 4$ chains, despite the absence of BM formation (Yang et al., 2005). The questions of whether the Schwann cells in distal nerves require an immaculate BM to segregate and myelinate the axons and/or whether the need for specific interactions between BM components and Schwann cell receptors is more critical than the assembly of the BM thus remain unsettled. Based on the location of collagen XV at the BM-matrix interface, rather than being embedded in the BM, and on the distinctive phenotype of the Col15 $\mathrm{al}^{-/-}$mice, we propose that collagen XV plays a role in supporting the BM-fibrillar matrix interface and, thus, supports the Schwann cells in the organization of C-fibers and the segregation of the axons. Such a role is supported by our ongoing work demonstrating a reduced collagen fibril diameter in young Col15a1 ${ }^{-1-}$ mice at endothelial and Schwann cell BM-fibrillar matrix interfaces and abnormal aggregation of the BM-associated collagen fibrils in adult mice (K. Rasi, unpublished results).

In summary (Fig. 8), we propose that a lack of collagen XV at the BM zone of mouse nerves may lead to a failure of signaling to the Schwann cells and, thereby, to persistent polyaxonal myelination, defective C-fiber formation, reduced myelin thickness, and poorer conduction along the sensory nerve fibers. This is the first in vivo evidence indicating that collagens play important physiological roles in axonal segregation and myelination by Schwann cells. We raise the possibility that collagen XV may be involved in the development of human peripheral neuropathies, many of which are currently of unknown etiology. Hereditary sensory and autonomic neuropathies (HSAN I) are characterized by distal sensory loss, autonomic disturbances, and, to some extent, muscle weakness (Auer-Grumbach, 2008). Three genetic loci, 9q22.1-22.3, 3p22-24, and 3q21, and seven HSAN I diseasecausing genes have been identified, but these explain $<20 \%$ of the patients (Nicholson et al., 1996; Dawkins et al., 2002; Klein et al., 2005; Auer-Grumbach, 2008; Rotthier et al., 2009). Even the most common causative gene, SPTLC1 on $9 q 22$, is mutated in only a small amount of patients. In light of our data on the Col15a1 $1^{-/-}$mice and the known location of the human COL15a1 gene on 9q21-22 (Hägg et al., 1998), we propose that this gene may be involved in some cases of HSAN.

\section{References}

Amenta PS, Scivoletti NA, Newman MD, Sciancalepore JP, Li D, Myers JC (2005) Proteoglycan-collagen XV in human tissues is seen linking banded collagen fibers subjacent to the basement membrane. J Histochem Cytochem 53:165-176.

Auer-Grumbach M (2008) Hereditary sensory neuropathy type I. Orphanet $\mathrm{J}$ Rare Dis 3:7.

Avila R, Beresford NA, Agüero A, Broed R, Brown J, Iospje M, Robles B, Suañez A (2004) Study of the uncertainty in estimation of the exposure of non-human biota to ionising radiation. J Radiol Prot 24:A105-A122.

Avila RL, Inouye H, Baek RC, Yin X, Trapp BD, Feltri ML, Wrabetz L, Kirschner DA (2005) Structure and stability of internodal myelin in mouse models of hereditary neuropathy. J Neuropathol Exp Neurol 64:976-990.

Blanton TN, Huang TC, Toraya H, Hubbard CR, Robie SB, Louër D, Göbel HE, Will G, Gilles R, Raftery T (1995) JCPDS-International Centre for Diffraction Data Round Robin Study of Silver Behenate. A possible low-angle x-ray diffraction calibration standard. J Powder Diffraction 10:91-95.

Carey DJ, Todd MS (1986) A cytoskeleton-associated plasma membrane heparan sulfate proteoglycan in Schwann cells. J Biol Chem 261:75187525.

Chernousov MA, Rothblum K, Stahl RC, Evans A, Prentiss L, Carey DJ (2006) Glypican-1 and $\alpha 4(\mathrm{~V})$ collagen are required for Schwann cell myelination. J Neurosci 26:508-517.
Dawkins JL, Brahmbhatt S, Auer-Grumbach M, Wagner K, Hartung HP, Verhoeven K, Timmerman V, De Jonghe P, Kennerson M, LeGuern E, Nicholson GA (2002) Exclusion of serine palmitoyltransferase long chain base subunit 2 (SPTLC2) as a common cause for hereditary sensory neuropathy. Neuromuscul Disord 12:656-658.

Eklund L, Piuhola J, Komulainen J, Sormunen R, Ongvarrasopone C, Fássler R, Muona A, Ilves M, Ruskoaho H, Takala TE, Pihlajaniemi T (2001) Lack of type XV collagen causes a skeletal myopathy and cardiovascular defects in mice. Proc Natl Acad Sci U S A 98:1194-1199.

Eldridge CF, Bunge MB, Bunge RP, Wood PM (1987) Differentiation of axon-related Schwann cells in vitro. I. ascorbic acid regulates basal lamina assembly and myelin formation. J Cell Biol 105:1023-1034.

Eldridge CF, Bunge MB, Bunge RP (1989) Differentiation of axon-related Schwann cells in vitro. II. Control of myelin formation by basal lamina. J Neurosci 9:625-638.

Feltri ML, Graus Porta D, Previtali SC, Nodari A, Migliavacca B, Cassetti A, Littlewood-Evans A, Reichardt LF, Messing A, Quattrini A, Mueller U, Wrabetz L (2002) Conditional disruption of beta 1 integrin in Schwann cells impedes interactions with axons. J Cell Biol 156:199-209.

Fernandez-Valle C, Gorman D, Gomez AM, Bunge MB (1997) Actin plays a role in both changes in cell shape and gene-expression associated with Schwann cell myelination. J Neurosci 17:241-250.

Hägg PM, Muona A, Liétard J, Kivirikko S, Pihlajaniemi T (1998) Complete exon-intron organization of the human gene for the alphal chain of type $\mathrm{XV}$ collagen (COL15A1) and comparison with the homologous COL18A1 gene. J Biol Chem 273:17824-17831.

Hurskainen M, Ruggiero F, Hägg P, Pihlajaniemi T, Huhtala P (2010) Recombinant human collagen XV regulates cell adhesion and migration. J Biol Chem 285:5258-5265.

Kimura J (2001) Part III, Assessment of neuromuscular transmission. 10, Techniques of repetitive stimulation. In: Electrodiagnosis in diseases of nerve and muscle. Principles and practice, pp 257-278. New York: Oxford UP.

Klein CJ, Wu Y, Kruckeberg KE, Hebbring SJ, Anderson SA, Cunningham JM, Dyck PJ, Klein DM, Thibodeau SN, Dyck PJ (2005) SPTLC1 and RAB7 mutation analysis in dominantly inherited and idiopathic sensory neuropathies. J Neurol Neurosurg Psychiatry 76:1022-1024.

Lathia JD, Patton B, Eckley DM, Magnus T, Mughal MR, Sasaki T, Caldwell MA, Rao MS, Mattson MP, ffrench-Constant C (2007) Patterns of laminins and integrins in the embryonic ventricular zone of the CNS. J Comp Neurol 505:630-643.

Martin JR, Webster HD (1973) Mitotic Schwann cells in developing nerve: their changes in shape, fine structure, and axon relationships. Dev Biol 32:417-431.

Moya F, Bunge MB, Bunge RP (1980) Schwann cells proliferate but fail to differentiate in defined medium. Proc Natl Acad Sci U S A 77:6902-6906.

Muona A, Eklund L, Väisänen T, Pihlajaniemi T (2002) Developmentally regulated expression of type $\mathrm{XV}$ collagen correlates with abnormalities in Col15a1(-/-) mice. Matrix Biol 21:89-102.

Nakagawa M, Miyagoe-Suzuki Y, Ikezoe K, Miyata Y, Nonaka I, Harii K, Takeda S (2001) Schwann cell myelination occurred without basal lamina formation in laminin alpha2 chain-null mutant (dy3K/dy3K) mice. Glia 35:101-110.

Nicholson GA, Dawkins JL, Blair IP, Kennerson ML, Gordon MJ, Cherryson AK, Nash J, Bananis T (1996) The gene for hereditary sensory neuropathy type I (HSN-I) maps to chromosome 9q22.1-q22.3. Nat Genet 13:101-104.

Patton BL, Miner JH, Chiu AY, Sanes JR (1997) Distribution and function of laminins in the neuromuscular system of developing, adult, and mutant mice. J Cell Biol 139:1507-1521.

Patton BL, Connoll AM, Martin PT, Cunningham JM, Mehta S, Pestronk A, Miner JH, Sanes JR (1999) Distribution of ten laminin chains in dystrophic and regenerating muscles. Neuromuscul Disord 9:423-433.

Patton BL, Cunningham JM, Thyboll J, Kortesmaa J, Westerblad H, Edström L, Tryggvason K, Sanes JR (2001) Properly formed but improperly localized synaptic specializations in the absence of laminin alpha4. Nat Neurosci 4:597-604.

Petäjäniemi N, Korhonen M, Kortesmaa J, Tryggvason K, Sekiguchi K, Fujiwara H, Sorokin L, Thornell LE, Wondimu Z, Assefa D, Patarroyo M, Virtanen I (2002) Localization of laminin alpha4-chain in developing and adult human tissues. J Histochem Cytochem 50:1113-1130. 
Pihlajaniemi T, Rehn M (1995) Two new collagen subgroups: membraneassociated collagens and types XV and XVII. Prog Nucleic Acid Res Mol Biol 50:225-262.

Rotthier A, Baets J, De Vriendt E, Jacobs A, Auer-Grumbach M, Lévy N, Bonello-Palot N, Kilic SS, Weis J, Nascimento A, Swinkels M, Kruyt MC, Jordanova A, De Jonghe P, Timmerman V (2009) Genes for hereditary sensory and autonomic neuropathies: a genotype-phenotype correlation. Brain 132:2699-2711.

Stanley EF (1981) Sensory and motor nerve conduction velocities and the latency of the $\mathrm{H}$ reflex during growth of the rat. Exp Neurol 71:497-506.

Stewart HJ, Morgan L, Jessen KR, Mirsky R (1993) Changes in DNA synthesis rate in the Schwann cell lineage in vivo are correlated with the precursor-Schwann cell transition and myelination. Eur J Neurosci 5:1136-1144.

Thyboll J, Kortesmaa J, Cao R, Soininen R, Wang L, Iivanainen A, Sorokin L, Risling M, Cao Y, Tryggvason K (2002) Deletion of the laminin alpha4 chain leads to impaired microvessel maturation. Mol Cell Biol 22:1194-1202.

Võikar V, Kõks S, Vasar E, Rauvala H (2001) Strain and gender differences in the behavior of mouse lines commonly used in transgenic studies. Physiol Behav 72:271-281.

Wallquist W, Patarroyo M, Thams S, Carlstedt T, Stark B, Cullheim S, Hammarberg H (2002) Laminin chains in rat and human peripheral nerve: distribution and regulation during development and after axonal injury. J Comp Neurol 454:284-293.

Wallquist W, Plantman S, Thams S, Thyboll J, Kortesmaa J, Lännergren J, Domogatskaya A, Ogren SO, Risling M, Hammarberg H, Tryggvason K, Cullheim S (2005) Impeded interaction between Schwann cells and axons in the absence of laminin $\alpha 4$. J Neurosci 25:3692-3700.

Webster HD, Martin R, O'Connell MF (1973) The relationships between interphase Schwann cells and axons before myelination: a quantitative electron microscopic study. Dev Biol 32:401-416.

Yang D, Bierman J, Tarumi YS, Zhong YP, Rangwala R, Proctor TM, Miyagoe-Suzuki Y, Takeda S, Miner JH, Sherman LS, Gold BG, Patton BL (2005) Coordinate control of axon defasciculation and myelination by laminin-2 and -8. J Cell Biol 168:655-666.

Yurchenco PD, Patton BL (2009) Developmental and pathogenic mechanisms of basement membrane assembly. Curr Pharm Des 15:1277-1294. 